\title{
Taurine Concentrations in Plasma, Blood Cells, and Urine of Children Undergoing Long-Term Total Parenteral Nutrition
}

\author{
NANCY E. VINTON, STEWART A. LAIDLAW, MARVIN E. AMENT, AND JOEL D. KOPPLE \\ Departments of Medicine and Pediatrics, Schools of Medicine and Public Health, Harbor-UCLA Medical Center \\ and UCLA Center for the Health Sciences, Torrance and Los Angeles, California
}

\begin{abstract}
Taurine concentrations in plasma, platelets, lymphocytes, granulocytes, erythrocytes, and urine were measured in 19 children who were undergoing long-term home parenteral nutrition for $27.4 \pm 7.1$ (SEM) months. The parenteral solutions contained methionine, but not taurine or cysteine. The patients' plasma, platelet, and urine taurine concentrations were significantly reduced to 54,48 , and $16 \%$, respectively, of the values from normal children of similar ages. The most significant reductions in plasma and platelet taurine concentrations were observed in the children who were estimated to absorb less than $5 \%$ of their daily calorie needs from the enteral tract. Lymphocyte and erythrocyte taurine levels tended to be lower but were not significantly different from those in normal children. The patients' plasma methionine and cystine levels were not different from normal. There was a direct correlation between plasma and platelet taurine concentrations and between plasma and urine taurine. Both plasma and platelet taurine tended to be directly correlated with age and, after the 1st yr of total parenteral nutrition, with the duration of total parenteral nutrition therapy. (Pediatr Res 21: 399-403, 1987)
\end{abstract}

Abbreviations

TPN, total parenteral nutrition

ERG, electroretinograms

SSA, sulfosalicylic acid

CSAD, cysteine sulfinic acid decarboxylase

The question of whether taurine (2-aminoethanesulfonic acid) may be an indispensable amino acid for humans has been the subject of much research in recent years. Studies in premature and term infants have shown that a low or absent dietary taurine intake (either from formula feedings or parenteral nutrition solutions) is associated with low plasma and urine taurine levels $(1-5)$. We have previously reported that children undergoing long-term TPN at home with solutions that do not contain taurine have low plasma taurine levels and abnormal ERG (6). These studies suggest that taurine is an indispensable amino acid.

However, taurine, which is one of the most abundant free amino acids (i.e. not bound in peptides or protein) in the human body, resides almost entirely within the cell. Intracellular taurine

Received August 11, 1986; accepted December 2, 1986.

Correspondence and reprint requests Joel D. Kopple, M.D., Harbor-UCLA Medical Center, 1000 W. Carson Street, Torrance, CA 90509.

Supported by NIH Grant 5 RO1 AM33112 and a grant from Travenol Laboratories, Inc. N.E.V. was the recipient of an NIH Individual National Research Service Award I F32 AM07550. concentrations are usually among the highest of any amino acid, while plasma taurine concentrations normally are rather low in comparison to other plasma amino acid levels (7-13). Thus, even though the plasma taurine concentrations in patients not receiving exogenous taurine are low, this may not reflect the status of the intracellular or total body pools of taurine. Abnormally low plasma taurine could reflect an intracellular shift rather than a reduction in body taurine pools. To obtain information as to whether a chronically low or absent taurine intake leads to depletion of the large intracellular compartments of taurine in the body, we measured taurine concentrations in the most readily accessible cells-platelets, lymphocytes, granulocytes, and red cells-as well as in plasma and urine. Specimens were obtained from normal children and children undergoing long-term parenteral nutrition without taurine.

\section{METHODS}

The study group consisted of 19 infants and children, aged $53.6 \pm 11.4$ (SEM) months, who had undergone home parenteral nutrition for an average of $27.4 \pm 7.4$ months. Thirteen of the 19 children began TPN within the 1 st month of life. The indications for parenteral nutrition in the children are listed in Table 1. The most common indication was congenital short bowel syndrome; this was present in seven children, each of whom had a small intestine length of less than $30 \mathrm{~cm}$. The child with proteinlosing enteropathy from radiation enteritis had been free of tumor (neuroblastoma) for $2.5 \mathrm{yr}$ when he was studied. At the time of blood sampling, all patients were clinically stable. Fourteen children (six males, eight females) served as normal controls. Their mean age was $63.2 \pm 10.1$ months, which was not different from the patient group.

Every 2 or 3 months the patients or their parents underwent a dietary interview with a 24 -h recall that was sometimes augmented with a 3-day dietary diary. All dietary interviews were conducted by a single research dietician. The quantity of calories absorbed from the intestinal tract was estimated from dietary histories, serum carotene levels, and from knowledge of whether the remaining length of small intestine was too short to allow absorption of substantial calories. Some children also underwent $72-\mathrm{hr}$ fecal fat measurements. These estimates were made without knowledge of the patient's plasma, blood cell, or urine taurine concentrations. Patients were classified into group 1 (11 patients) or group 2 (eight patients) according to whether their estimated daily enteral absorption of calories was either less than $5 \%$ or $5 \%$ or greater of their requirement. Two group 1 patients did not eat at all. In contrast, three group 2 patients were estimated to absorb between 35 and $50 \%$ of their estimated energy needs.

Patients were infused with 1 to 3 liter/day of solutions which contained dextrose, 15 to $25 \%$, and amino acids, 2.0 or $4.25 \%$ Travasol (Travenol Laboratories, Deerfield, IL) that provided 
Table 1. Characteristics of children undergoing long-term parenteral nutrition

\begin{tabular}{ll}
\multicolumn{2}{c}{ parenteral nutrition } \\
\multicolumn{2}{c}{$\begin{array}{c}\text { Children } \\
(n=19)\end{array}$} \\
\hline Males/females & $12 / 7$ \\
Age (mo) & $53.6(2-170)^{*}$ \\
Duration of TPN (mo) & $27.4(1-92)^{*}$ \\
Gastrointestinal disorders & \\
Jejunoileal atresia & 7 \\
Chronic idiopathic intestinal pseudoobstruction & 4 \\
Trauma to pancreatic-biliary tree/intestine & 3 \\
Mid-gut volvulus & 2 \\
Omphalocele/gastroschisis & 2 \\
Radiation enteritis & 1 \\
\hline
\end{tabular}

* Values are expressed as mean and range.

800 to $1700 \mathrm{mg} /$ liter methionine and no cysteine. Lipids were provided from 1 to 7 days each week as 10 or $20 \%$ Intralipid (Cutter Laboratories, Emeryville, CA) or 10\% Liposyn (Abbott Laboratories, North Chicago, IL). Vitamin $\mathrm{B}_{6}$, an enzyme cofactor in the pathway of taurine biosynthesis, was supplied in the standard intravenous vitamin preparations, MVI-12 $(4.0 \mathrm{mg}$ pyridoxine $\mathrm{HCl} /$ day, $82.6 \%$ pyridoxine, supplied in a $10-\mathrm{ml}$ vial) or MVI-Pediatric (1.0 mg pyridoxine $\mathrm{HCl} /$ day in a $5-\mathrm{ml}$ vial) (USV-Revlon, Tarrytown, NY). MVI-Pediatric was only given to children less than $1 \mathrm{yr}$ of age. Trace element additives to the TPN solutions included zinc, $2 \mathrm{mg} / \mathrm{liter}$, copper, $1 \mathrm{mg} / \mathrm{liter}$, selenium, $20 \mu \mathrm{g} /$ liter, and chromium, $2 \mu \mathrm{g} /$ liter. Parenteral nutrition was infused over an 8 - to 12 -h period starting at about 2000 to $2200 \mathrm{~h}$ as previously described (14). Fifteen patients received parenteral nutrition daily, and in three group 2 patients parenteral nutrition was administered 6 days per week.

Blood for amino acid analysis was drawn from each patient on a single occasion between 1300 and $1600 \mathrm{~h}$ during the postabsorptive state $(6-8 \mathrm{~h}$ after completion of the nightly parenteral infusion and 6-8 h after their last meal if they ate). Blood was obtained from the normal controls postabsorptively, between 1300 and $1500 \mathrm{~h}, 6-8 \mathrm{~h}$ after their last meal. The blood was anticoagulated with EDTA or heparin and placed on ice. Plasma and blood cells were separated and prepared for amino acid analysis as previously described (13). Plasma was deproteinized with SSA, $22.5 \mathrm{mg}$ for each $0.5 \mathrm{ml}$ plasma. Blood cells were separated on Percoll gradients, by a method adapted from Pertoft et al. (15). The various cell layers were separated and then pelleted and resuspended several times in $0.15 \mathrm{M} \mathrm{NaCl}$ to wash the cells. Finally, $250 \mu \mathrm{l}$ of $5 \%(\mathrm{w} / \mathrm{v}) \mathrm{SSA}$ were added to the cell pellets, and the deproteinized supernatant was removed after centrifugation. Control studies indicated that the contamination of any cell fraction with other types of blood cells was small and did not affect the measured taurine concentrations (13). Attempts were made to collect 24-h urine specimens, but usually the quantity obtained was less than a full day's collection. Therefore, urine creatinine was also measured, and the urine amino acid concentrations are expressed per $g$ of creatinine.

The urine and deproteinized plasma and blood cell specimens were frozen overnight at $-20^{\circ} \mathrm{C}$ and thereafter at $-70^{\circ} \mathrm{C}$ until analysis. Samples were analyzed for amino acids within 14 days of collection with a Beckman 121 MB Amino Acid Analyzer (Beckman Instruments Inc., Fullerton, CA) using a single column, 3 buffer lithium citrate elution system as previously described (16). Taurine was measured in plasma, platelets, lymphocytes, granulocytes, erythrocytes, and urine. Methionine and cystine were measured only in plasma because the yield of these amino acids from blood cells by our techniques was too low to quantify. Creatinine was measured by the picric acid method using a Beckman creatinine analyzer.

Nutritional assessment was carried out using standard anthropometric techniques (17-19) and included height or length de- pending on maturation of the child, body weight, midarm circumference, arm muscle area, and triceps and subscapular skinfold thickness. These findings are reported as Z-scores, calculated for chronologic age, as previously described (18). Data for normal children were taken from the HANES I study and the analyses of Frisancho $(19,20)$. Serum creatinine, albumin, triglycerides, cholesterol, glutamate-oxaloacetate transaminase, bilirubin, and alkaline phosphatase were measured in the UCLA Clinical Laboratories. Zinc levels were determined by atomic absorption spectrophotometry, vitamin $\mathrm{B}_{6}$ by radioenzymetric assay of pyridoxal-5-phosphate activation of tyrosine decarboxylase, and vitamin A by HPLC (American Bioscience Laboratories, Van Nuys, CA).

Statistical analyses were carried out by multiple $t$ tests. For the statistical comparison of taurine concentrations in plasma, blood cells, and urine, a preliminary comparison was carried out between the values in the normal control subjects and in all 19 patients using the Bonferroni method (21). Since taurine was measured in six different biologic fluids or cells, the large number of comparisons might be expected to randomly yield some differences significant at the 0.05 level. Therefore, for the difference in values between the normal subjects and the 19 patients to attain statistical significance at $p<0.05$, the calculated $p$ value for an individual comparison had to be $<0.008$ (i.e. 0.05 divided by the six separate comparisons). For the three-way comparisons between the normal subjects and the two patient groups (normal versus group 1, normal versus group 2, group 1 versus group 2), a difference in values was considered statistically significant at $p$ $<0.05$ if the calculated $p$ value was 0.0028 or lower $(0.05$ divided by 18 comparisons). If these latter $p$ values were statistically significant by this screening criterion, then the actual $p$ value, calculated by a simple nonpaired $t$ test, is reported. Correlations between concentrations in plasma, urine, or blood cells were performed by linear regression analysis. Variance is expressed as SEM. These studies wee approved by the UCLA Human Subject Protection Committee.

\section{RESULTS}

The estimated parenteral and oral intake and enteral absorption of calories of the patients are shown in Table 2 . The enteral

Table 2. Nutritional intake of children undergoing long-term parenteral nutrition

$\begin{array}{ccc}\begin{array}{c}\text { All patients } \\ (n=19)\end{array} & \begin{array}{c}\text { Group 1* } \\ (n=11)\end{array} & \begin{array}{c}\text { Group 2* } \\ (n=8)\end{array}\end{array}$

Intake from parenteral nu-

trition

Cal $(\mathrm{kcal} / \mathrm{kg} /$ day)

D-glucose $(\mathrm{g} / \mathrm{kg} /$ day $)$

Lipid $(\mathrm{g} / \mathrm{kg} /$ day)

Amino acids $(\mathrm{g} / \mathrm{kg} /$ day $)$

Methionine ( $\mathrm{g} / \mathrm{kg} /$ day)

Oral food intake

Quantity estimated to be ingested

$\mathrm{Cal}$ (kcal/kg/day)

Carbohydrate $(\mathrm{g} / \mathrm{kg} /$ day)

Fat $(\mathrm{g} / \mathrm{kg} /$ day $)$

Protein $(\mathrm{g} / \mathrm{kg} /$ day)

$\begin{array}{ccc}54.5 \pm 5.8 \dagger & 65.3 \pm 6.6 & 34.5 \pm 4.2 \\ 14.4 \pm 1.6 & 16.1 \pm 1.6 & 8.7 \pm 1.2 \\ 0.90 \pm 0.17 & 0.95 \pm 0.22 & 0.45 \pm 0.16 \\ 1.5 \pm 0.1 & 1.6 \pm 0.1 & 1.1 \pm 0.1 \\ 51.2 \pm 3.1 & 57.7 \pm 3.1 & 39.3 \pm 2.4\end{array}$

$\begin{array}{lll}51.2 \pm 3.1 & 57.7 \pm 3.1 & 39.3 \pm 2.4\end{array}$

Quantity estimated to be absorbed

Cal (kcal/kg/day)

$20.8 \pm 6.0 \quad 8.7 \pm 2.3 \quad 51.7 \pm 11.3$

$2.86 \pm 1.12 \quad 1.40 \pm 0.59 \quad 8.20 \pm 2.41$

$0.79 \pm 0.32 \quad 0.39 \pm 0.16 \quad 2.23 \pm 0.72$

$0.62 \pm 0.24 \quad 0.3 \pm 0.1 \quad 1.4 \pm 0.6$

* Group 1 and Group 2 patients are estimated to absorb from the enteral tract less than $5 \%$ and greater than $5 \%$, respectively, of their estimated daily calorie needs.

$\dagger$ Mean \pm SEM 
intake of food was very limited in group 1 patients. Five of the group 1 patients absorbed less than $2 \%$ of their daily calorie needs from the enteral tract. Only three patients in group 2 were estimated to absorb greater than $25 \%$ of their daily calorie requirements from the intestinal tract.

The clinical and biochemical parameters of nutritional status are shown in Table 3 . The height and weight of these patients were generally within one Z-score measure of normal values, calculated for chronologic age, although the patients tended to be of short stature and to weigh more than normal. Arm muscle area and triceps skinfold thickness was significantly increased in comparison to published normal values (19). Serum total protein, albumin, zinc, and vitamin $\mathrm{A}$ and plasma vitamin $\mathrm{B}_{6}$ values were normal.

The plasma, blood cell, and urine taurine concentrations are shown in Table 4. In the combined group of 19 patients, taurine levels were significantly decreased in plasma, platelets, and urine by 40,42 , and $84 \%$, respectively, as compared to normal controls. In the group 1 patients, these reductions were even greater and averaged 58,59 , and $84 \%$, respectively, of the control values in plasma, platelets, and urine. In the group 2 patients, the taurine concentrations were less reduced and only significantly decreased in urine. There was also a tendency, not statistically

Table 3. Anthropometric and biochemical measures of nutritional status in children undergoing long-term TPN

Patients $(n=19)$

$\begin{array}{lc}\text { Anthropometry } & 99.8 \pm 7.7^{*} \\ \text { Ht }(\mathrm{cm}) & -1.0 \pm 0.4 \uparrow^{a} \\ \text { Z-score } \dagger & 23.1 \pm 4.9 \\ \text { Wt }(\mathrm{kg}) & +0.9 \pm 0.5 \\ \text { Z-scorc } & 26.0 \pm 6.2(9) \\ \text { Arm muscle area }\left(\mathrm{mm}^{2}\right) & +1.9 \pm 0.1(9) \ddagger^{b} \\ \text { Z-score } & 14.3 \pm 5.3(9) \\ \text { Triceps skinfold (mm) } & +1.5 \pm 0.7(9) \ddagger^{a} \\ \text { Z-score } & 6.9 \pm 0.4(9) \\ \text { Subscapular skinfold (mm) } & \\ \text { Serum chemistries } & 0.6 \pm 0.1(17) \\ \text { Creatinine (mg/dl) } & 3.9 \pm 0.1(17) \\ \text { Albumin (g/dl) } & 92 \pm 13(14) \\ \text { Triglycerides (mg/dl) } & 126 \pm 7(16) \\ \text { Cholesterol (mg/dl) } & 71 \pm 12(17) \\ \text { GOT (U/l) } & 1.0 \pm 0.3(17) \\ \text { Total bilirubin (mg/dl) } & 263 \pm 24(17) \\ \text { Alkaline phosphatase (U/l) } & 101.8 \pm 10.1(9) \\ \text { Zinc (ng/dl) } & 20.4 \pm 2.6(8) \\ \text { Vitamin } \mathrm{B}_{6}(\mathrm{ng} / \mathrm{dl}) & 77 \pm 12(9) \\ \text { Vitamin A (mg/dl) } & \end{array}$

* Mean \pm SEM. Numbers in parentheses indicate number of samples obtained if less than total number of subjects studied.

$\dagger Z$-scores calculated for chronologic age (18).

\$ Statistically different from normals: ${ }^{a} p<0.05,{ }^{b} p<0.001$. significant, for plasma, platelet, and lymphocyte taurine to be lower in group 1 as compared to group 2 children.

The reduced urine taurine/creatinine ratios in the TPN patients may underestimate the degree of reduction in their urine taurine excretion because urine creatinine concentrations tended to be lower in the TPN patients $(39.1 \pm 9.0 \mathrm{mg} / \mathrm{dl})$ although not significantly so compared to the normal children (52.2 \pm 9.1 $\mathrm{mg} / \mathrm{dl}$ ). The lower urine creatinine levels in the TPN patients probably reflect their lower dietary intake of creatine and creatinine.

Plasma methionine and cystine levels in group 1 and group 2 patients did not differ from the values in normal children and were not different in group 1 as compared to group 2 (Table 5). However, two children in group 2 but no patients in group 1 had plasma cystine concentrations more than 2 SDs below the normal mean. In no patient was the plasma methionine level 2 SDs below the normal mean. No significant relationship was observed between the amount of methionine supplied from the TPN solutions and plasma methionine, cystine, or taurine.

There was a direct correlation between taurine levels in plasma and platelets $(r=0.61, n=19, p<0.01)$ and in plasma and urine $(r=0.79, n=10, p<0.01)$ as shown in Figures 1 and 2 (in each case, a single outlier has been excluded from the calculated analysis). There was also a direct correlation between the age of the children and platelet taurine concentrations $(r=0.46$, $n=19, p<0.05$; excluding the outlier, $r=0.64, n=18, p<$ $0.01)$. Similarly, excluding one outlier, there was a correlation between age and plasma taurine levels $(r=0.63, n=18, p<$ 0.01 ). After the first 12 months of TPN, plasma and platelet taurine concentrations each correlated with the duration of TPN (plasma taurine: $r=0.77, n=7, p<0.05$; platelet taurine: excluding one outlier $r=0.82, n=6, p<0.01$ ). There were no other significant correlations between cellular taurine concentrations in the various cells, or between cellular taurine concentrations and age or duration of TPN.

\section{DISCUSSION}

Although taurine is not found in mammalian protein, it is the most or second most abundant free amino acid in the human body (7-12). There are approximately $10 \mathrm{~g}$ of taurine in adult humans, but there appears to be only a small rate of synthesis of taurine and few metabolic pathways (22). Premature and full-

Table 5. Fasting plasma methionine and cystine levels ( $\mu \mathrm{mol} /$ liter)

\begin{tabular}{llccc}
\hline & $\begin{array}{c}\text { Normal } \\
(n=14)\end{array}$ & $\begin{array}{c}\text { All patients } \\
(n=19)\end{array}$ & $\begin{array}{c}\text { Group 1 } \\
(n=11)\end{array}$ & $\begin{array}{c}\text { Group 2 } \\
(n=8)\end{array}$ \\
\hline Methionine & $24 \pm 2^{*}$ & $27 \pm 3$ & $30 \pm 3$ & $23 \pm 6$ \\
Cystine & $40 \pm 4$ & $31 \pm 4$ & $33 \pm 5$ & $29 \pm 5$ \\
\hline
\end{tabular}

$*$ Mean \pm SEM. For each amino acid, there are no significant differences among groups.

Table 4. Fasting plasma, blood cell, and urine taurine levels in children undergoing long-term TPN

\begin{tabular}{|c|c|c|c|c|}
\hline & $\begin{array}{l}\text { Normals } \\
(n=14)\end{array}$ & $\begin{array}{l}\text { All patients } \\
(n=19)\end{array}$ & $\begin{array}{l}\text { Group 1* } \\
(n=11)\end{array}$ & $\begin{array}{c}\text { Group } 2 \dagger \\
(n=8)\end{array}$ \\
\hline Plasma ( $\mu \mathrm{mol} /$ liter $)$ & $52 \pm 3 \ddagger$ & $28 \pm 4 \S^{b}$ & $22 \pm 4^{b}$ & $36 \pm 8$ \\
\hline Platelets (nmol/ $10^{9}$ cells) & $294 \pm 23(12)$ & $169 \pm 30^{a}$ & $120 \pm 20^{b}$ & $239 \pm 59$ \\
\hline Lymphocytes (nmol/ $10^{9}$ cells) & $4845 \pm 571(13)$ & $3266 \pm 577(17)$ & $2806 \pm 729(10)$ & $3922 \pm 946(7)$ \\
\hline Granulocytes (nmol $/ 10^{9}$ cells) & $11268 \pm 1899(10)$ & $14383 \pm 2594(17)$ & $14869 \pm 3618(10)$ & $13687 \pm 3922(7)$ \\
\hline Erythrocytes (nmol/10 $10^{9}$ cells) & $4.2 \pm 0.5(12)$ & $3.4 \pm 0.7$ & $3.6 \pm 1.0$ & $2.9 \pm 1.0$ \\
\hline Urine (mg/g creatinine) & $182 \pm 87(11)$ & $30 \pm 3.9(12)^{b}$ & $29 \pm 5.3(7)^{b}$ & $30 \pm 6.3(5)^{b}$ \\
\hline
\end{tabular}

* Group 1 are children estimated to absorb enterally less than $5 \%$ of their calculated energy needs.

$\dagger$ Group 2 are children estimated to absorb enterally greater than $5 \%$ of their calculated energy needs.

$\ddagger$ Mean \pm SEM. Numbers in parentheses indicate the sample size when it is less than the total number of individuals in the group.

$\S$ Statistically different from normals: ${ }^{a} p<0.005,{ }^{b} p<0.001$. 


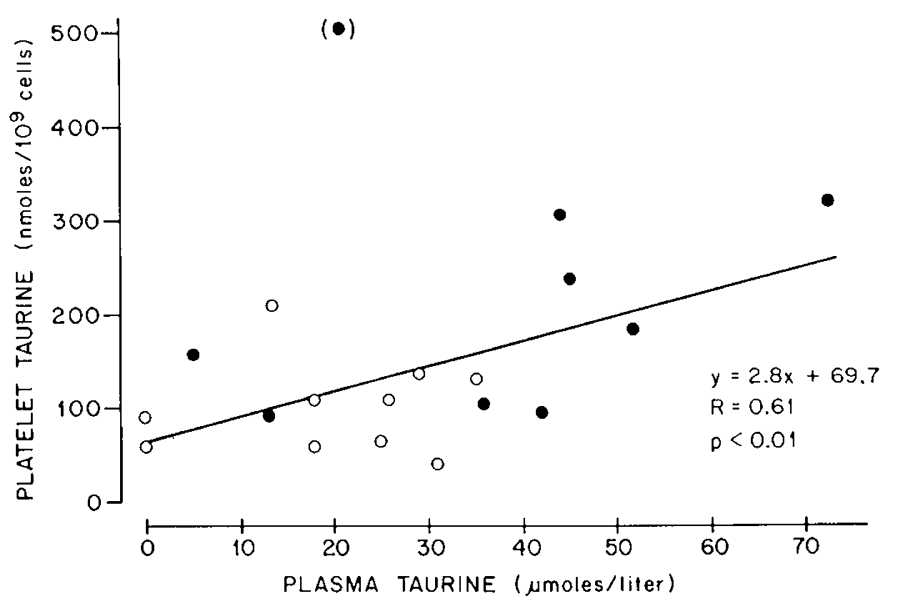

Fig. 1. The direct correlation between plasma and platelet taurine concentrations in 19 children undergoing long-term TPN without taurine. Open and closed circles indicate the patients in whom enteral absorption of calories was estimated to be less than $5 \%$ (group 1) or greater than $5 \%$ (group 2), respectively, of their daily calorie requirements. The diagonal line indicates the least squares regression equation. The one outlier with a platelet taurine concentration of $578 \mathrm{nmol} / 10^{9}$ cells was omitted from these calculations.

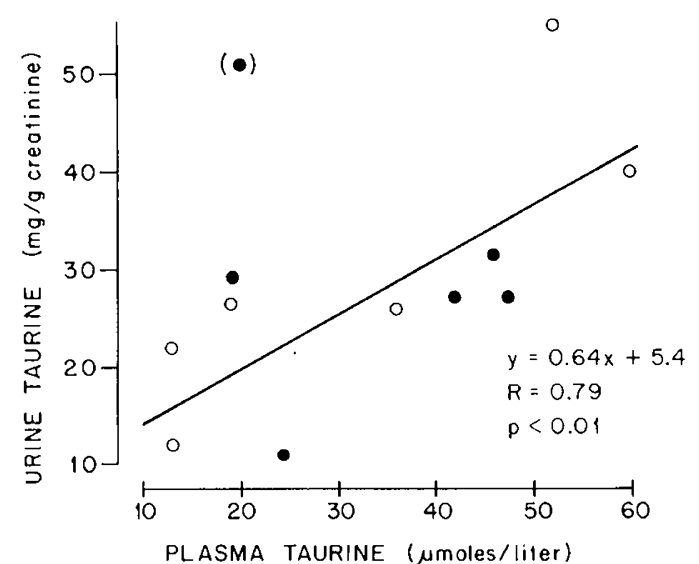

Fig. 2. The direct correlation between plasma and urine taurine in 10 children undergoing long-term TPN without taurine. Symbols are described in the legend to Figure 1.

term newborns who are fed formula diets or given parenteral nutrition lacking taurine have decreased plasma and urine taurine; however their growth rate, nitrogen balance and serum albumin, globulin, cholesterol, and urea concentrations remain normal (1-5). In a previous study we showed that children undergoing long-term TPN without taurine had low plasma taurine levels (6).

Since most of the taurine in the body is intracellular, it is possible that intracellular taurine and total body taurine may be normal even though plasma pools are reduced. The present study was, therefore, undertaken to examine whether intracellular taurine concentrations in blood cells are reduced in children undergoing long-term TPN without taurine and who have little or no enteral taurine intake. The results indicate that taurine levels are reduced in plasma, platelets, and urine of the longterm TPN patients, and that the values are particularly low in the group 1 patients who had the lowest intake and absorption of food. Group 2 contained three children who had a much greater degree of intestinal absorption $(35-50 \%$ of their daily energy requirements). This may explain why this group showed no significant reductions in plasma or cellular taurine levels although their mean values tended to be lower than those of normal controls. It should also be noted that the Bonferroni method used for statistical analysis of differences between groups is an extremely conservative one; this method may not reveal small differences between groups which are nevertheless real (21).

There are few pathways for taurine metabolism in humans $(7$, $8,22)$, and urinary taurine excretion may play an important role in regulating body taurine pools (23-26). Both group 1 and group 2 patients showed a remarkable degree of renal conservation of taurine; their urinary taurine excretion averaged $16 \%$ of normal (Table 4). This reduction in urinary taurine excretion is probably one factor contributing to the reason the plasma and blood cell taurine levels in those patients with greater enteral absorption were closer to normal.

The findings from the study are, in general, similar to our observations in adults undergoing long-term TPN without taurine (13). Plasma, platelet, lymphocyte, and red cell taurine concentrations were reduced in these individuals. Moreover, plasma and platelet values were lower in the adult patients who were estimated to absorb less than $25 \%$ of their estimated energy requirements than in those with greater intestinal absorption. Urine taurine excretion was also markedly reduced in both groups of adult patients (Vinton $\mathrm{N}$, unpublished observations).

In our pediatric TPN patients, both plasma and platelet taurine concentrations increased with age and, after the 1st yr of TPN, with duration of therapy. The plasma and platelet values still tended to be reduced in the oldest patients when compared to normal children (Table 4). This relationship between taurine concentrations and age or duration of TPN does not appear to be due to differences in intestinal absorption between the younger and older patients.

The hepatic activity of two key enzymes in the biosynthetic pathway for taurine, CSAD and cystathionase, are low in fetal liver $(8,27)$. In adult liver, CSAD activity remains low, while cystathionase activity rises $(8,27)$. Hence, it is possible that the increase in plasma and platelet taurine with age may be due to a greater ability to synthesize taurine.

The children undergoing longterm TPN did not receive intravenous cysteine and had reduced enteral uptake and absorption of this amino acid. Studies have shown that plasma cystine levels are low in neonates $(28,29)$, cirrhotic patients $(30,31)$ and normal adults $(31,32)$ receiving intravenous methionine as the only source of sulfur amino acids. Hence, it is possible that a low intake of cysteine, which is a metabolic precursor of taurine, or inadequate conversion of intravenously administered methionine, could contribute to low taurine levels in these patients. However, the mean plasma cystine levels were not significantly reduced in either group 1 or group 2 patients (Table 5), although two group 2 patients did have levels more than 2 SDs below normal. Hence, it is not readily apparent that lack of availability of cystine is the cause of the low taurine concentrations in our children on TPN. Further work is clearly necessary in this area.

Vitamin $B_{6}$ is a cofactor for three enzymes involved in the biosynthesis of taurine (cystathionine synthase, cystathionase, and CSAD). Since our patients routinely receive intravenous pyridoxine $\mathrm{HCl}$ and their plasma pyridoxal-5-phosphate values were normal, it does not seem likely that vitamin $\mathrm{B}_{6}$ deficiency impaired their taurine synthesis and caused low body taurine pools.

It is possible that the decreased intestinal mass or function in the long-term TPN patients in some way created a nutritional requirement for taurine that does not normally exist. Hence, the data from this study would not apply to normal children. This possibility is not considered to be likely because the children undergoing TPN had a number of different gastrointestinal disorders that caused this need for long-term TPN. Although some children had little or no intestinal tract or had chronic intestinal 
inflammation and scarring, other children appeared to have a normal-sized gastrointestinal tract that probably functioned abnormally because of neurologic lesions (Table 1).

The present findings of low plasma platelet and urine taurine levels in children undergoing long-term TPN without taurine suggest that these children have low body pools of this amino acid. Further studies are necessary to examine whether other intracellular taurine pools are also reduced in these patients, whether intravenous or oral cysteine will maintain normal taurine pools, and whether low taurine levels may cause adverse physiologic or clinical effects.

Acknowledgments. The authors thank Stella Wu, M.D. for careful amino acid analysis and cell separation and Mary Grosvenor, M.S. for carrying out nutritional assessment.

\section{REFERENCES}

1. Raiha NCR, Heinonen K, Rassin DK, Gaull GE 1976 Milk protein quantity and quality in low birth weight infants. I. Metabolic responses and effects on growth. Pediatrics 57:659-674

2. Gaull GE, Rassin DK, Raiha NCR, Heinonen K 1977 Milk protein quantity and quality in low birth weight infants. III. Effect on sulfur amino acids in plasma and urine. J Pediatr 90:348-355

3. Rigo J, Senterre J 1977 Is taurine essential for the neonate? Biol Neonate $32: 73-76$

4. Jarvenpaa A-L, Raiha NCR, Rassin DK, Gaull GE 1983 Feeding the low birth weight infant: I. Taurine and cholesterol supplementation of formula does not affect growth and metabolism. Pediatrics 71:171-178

5. Okamota E, Rassin DK, Zucker CL, Salen GS, Heird WC 1984 Role of taurine in feeding the low birth weight infant. J Pediatr 104:936-940

6. Geggel HS, Ament ME, Heckenlively JR, Martin DA, Kopple JD 1985 Nutritional requirement for taurine in patients receiving long-term parenteral nutrition. N Engl J Med 312:142-146

7. Hayes KC, Sturman JA 1981 Taurine in metabolism. Ann Rev Nutr 1:401425

8. Jacobsen JG, Smith LH 1968 Biochemistry and physiology of taurine and taurine derivatives. Physiol Rev 48:424-511

9. Aoki TT, Muller WA, Brennan MF, Cahill GF 1973 Blood cell and plasma amino acid levels across forearm muscle during a protein meal. Diabetes 22:768-775

10. McMenamy RH, Lund CC, Neville GJ, Wallach DFH 1960 Studies of unbound amino acid distribution in plasma, erythrocytes, leukocytes, and urine of normal human subjects. J Clin Invest 39:1675-1687

11. Bergstrom J, Furst P, Noree L-O, Vinnars E 1974 Intracellular free amino acid concentration in human muscle tissue. J Appl Physiol 36:693-697

12. Fukuda K, Usui $T 1983$ Characteristic patterns of free amino acid content in plasma, erythrocytes, lymphocytes and granulocytes in man. Hiroshima J Med Sch 32:163-166
13. Vinton NE, Laidlaw SA, Ament ME, Kopple JD 1986 Taurine concentrations in plasma and blood cells of patients undergoing longterm parenteral nutrition. Am J Clin Nutr 44:398-404

14. Byrne WJ, Ament ME, Burke M, Fonkalstrud E 1979 Home parenteral nutrition. Surg Gynecol Obstet 149:593-599

15. Pertoft H, Hirtenstein M, Kagdal L 1979 Cell separations in a new density medium, Percoll ${ }^{R}$. In: Reid E (ed) Cell Populations, Methodological Surveys. Biochemistry, Vol 9(B). Ellis Horwood, Ltd., Chichester, West Sussex, UK, pp 67-80

16. Flugel-Link RM, Jones MR, Kopple JD 1983 Red cell and plasma amino acid concentrations in renal failure. JPEN 7:450-456

17. Johnson CL, Fulwood R, Abraham S, Bryner JD 1981 Basic data on anthropometric measurements and angular measurements of hip and knee joints for selected age groups 1-74 years of age: United States 1971-1975. Vital and Health Statistics Series II no 219. National Center for Health Statistics. Hyattsville, MD. DHHS Publication no (PHS) 81-1669

18. Salusky IB, Fine RN, Nelson P, Blumenkrantz MJ, Kopple JD 1983 Nutritional status of children undergoing continuous ambulatory peritoneal dialysis. Am J Clin Nutr 38:599-611

19. Frisancho AR 1981 New norms of upper limb fat and muscle areas for assessment of nutritional status. Am J Clin Nutr 34:2540-2545

20. Hawill PVV 1977 Growth curves for children. Vital and Health Statistics Series II. Data from the National Health Survey, no 165. National Center for Health Statistics. Hyattsville, MD. DHEW Publication no (PHS) 78-1650

21. Godfrey K 1985 Statistics in practice. N Engl J Med 313:1450-1456

22. Sturman JA, Hepner GW, Hofmann AF, Thomas PJ 1975 Metabolism of ${ }^{35} \mathrm{~S}$ taurine in man. J Nutr 105:1206-1214

23. Chesney RW, Gusowski N, Friedman AL 1983 Renal adaptation in altered dietary sulfur amino acid intake occurs at luminal brush border membrane Kidney Int 24:588-594

24. Friedman AL, Albright PN, Gusowki N, Padilla M, Chesney RW 1983 Renal adaptation to alteration in dietary amino acid intake. Am $\mathrm{J}$ Physio 245:F159-F166

25. Evered DF, Harvey MS, Luck LJ, Solari ME 1969 The relationship between urinary taurine excretion and the intake of protein-rich foods. Life Sci 8:601605

26. Laidlaw SA, Shultz TD, Kopple JD 1986 Taurine levels in plasma and urine of vegans. Am J Clin Nutr 43:i (abstr)

27. Gaull GE Sturman JA, Raiha NCR 1972 Development of mammalian sulfur metabolism. Absence of cystathionase in human fetal tissues. Pediatr Res 6:538-547

28. Pohlandt F 1974 Cystine: a semi-essential amino acid in the newborn infant. Acta Paediatr Scand 63:801-804

29. Zlotkin SH, Bryan MH, Anderson GH 1981 Cysteine supplementation to cysteine-free intravenous feeding regimens in newborn infants. $\Lambda \mathrm{m} \mathrm{J}$ Clin Nutr 34:914-923

30. Chawla RK, Lewis FW, Kutner MH, Bate DM, Roy RGC, Rudman D 1984 Plasma cysteine, cystine, and glutathione in cirrhosis. Gastroenterology $87: 770-776$

31. Chawla RK, Berry CI, Kutner NH, Rudman D 1985 Plasma concentrations of transsulfuration pathway products during nasocnteral and intravenous hyperalimentation of malnourished patients. Am J Clin Nutr 42:577-584

32. Stegink LD, den Besten L 1972 Synthesis of cysteine from methionine in normal adult subjects: effect of route of alimentation. Science 178:5 14-516 